Ensino, Saúde e Ambiente - v. 14 n. esp. (2021): Dossiê Paulo Freire para além dos 100 anos:

construir utopias, transformar a realidade, p. 189-200.

Lutas Sociais e Educação Popular

ENSINO, SAÚDE E AMBIENTE

\title{
O “Novo Normal” Pandêmico e os Desafios para a Educação Crítica
}

\section{The Pandemic "New Normal” and Challenges for Critical Education}

\author{
Inny Accioly'; Donaldo Macedo
}

1 Professora Adjunta, Universidade Federal Fluminense, Rio de Janeiro, RJ, Brasil - E-mail: innyaccioly@gmail.com, / ORCID https://orcid.org/0000-0002-7726-4536

2 Professor Emérito, University of Massachusetts, Boston, Massachusetts, Estados Unidos - E-mail: donaldo.macedo@umb.edu, / ORCID https://orcid.org/0000-0002-6059-6489

Palavras-chave: educação crítica; pandemia; Paulo Freire; neoliberalismo.

\section{Keywords:} critical education; pandemic; Paulo Freire; neoliberalism.
RESUMO: O texto dialoga com a obra de Paulo Freire para reivindicar um olhar crítico e historicamente situado - a partir da perspectiva dos povos oprimidos sobre a realidade social e ambiental do capitalismo atual, especialmente no contexto da pandemia da COVID-19. Os autores buscam trazer elementos que auxiliem na compreensão da realidade em sua totalidade e globalidade, estabelecendo correlação entre eventos históricos e condições sociais, a fim de ir além da denúncia da "normalidade" neoliberal - e seus efeitos na educação, no meio ambiente, nas condições de vida nas periferias globais e na arquitetada "crise dos refugiados" para anunciar uma educação crítica que seja radicalmente centrada na igualdade e na defesa da vida.

\begin{abstract}
The article dialogues with Paulo Freire's work to argue for a critical and historically situated view - from the perspective of the oppressed - on the social and environmental reality of current capitalism, specifically in the context of the COVID-19 pandemic. The authors seek to bring elements that contribute to the understanding of reality in its entirety and globality, establishing correlations between historical events and social conditions, to go beyond the denunciation of neoliberal "normality" - and its effects on education, environment, on the living conditions in the global peripheries, and the so-called "refugee crisis" - to announce a critical education that is radically centered on equality and the defense of life.
\end{abstract}

\section{INTRODUÇÃO}

A pandemia da COVID-19, assim como a devastação provocada pelo furacão Katrina em Nova Orleans em 2005, são episódios que devem ser analisados para além do seu caráter de catástrofe biológica ou ambiental, pois, sobretudo, estes são fenômenos que desvelam o continuum histórico que anualmente vitima milhões de pessoas nas periferias 
Ensino, Saúde e Ambiente - v. 14 n. esp. (2021): Dossiê Paulo Freire para além dos 100 anos: construir utopias, transformar a realidade, p. 189-200.

\section{Lutas Sociais e Educação Popular}

globais. No caso da pandemia, não é de surpreender que, embora o vírus faça vítimas independentemente de etnia, raça, classe e gênero, as populações que são mais mortalmente afetadas são aquelas que sofreram um passado - que é prolongado no presente - de escravização, colonização e exploração.

A progressiva precarização das condições de vida a que estas populações estão sujeitas, somada à destruição dos sistemas públicos de saúde e sua subsequente privatização e o desmonte dos direitos trabalhistas impõem a necessidade de submissão a cargas de trabalho cada vez mais intensas e um dilema entre ou morrer de fome ou correr o risco de ser infectado no uso diário de sistemas de transporte público superlotados. Tais fatores, além de contribuírem para deprimir a resposta imunológica ao vírus, levam a maiores taxas de transmissão e mortalidade.

O fato é que, para as populações das favelas e periferias ao redor do mundo, a luta diária pela sobrevivência com um mínimo de dignidade os coloca permanentemente em "estado de emergência". Portanto, o alerta de emergência pandêmica não é uma exceção, mas a regra sob a qual suas vidas são governadas e controladas.

Diante do exposto, argumentamos que a necessária transformação social exige que nos recusemos a adotar posturas pessimistas frente à atualidade selvagem do capitalismo ou considerar tal situação como sendo imutável e inexorável. Ao contrário, é preciso compreender que o curso da história - não sendo um amontoado de fatos e ações desconectadas, mas um conjunto complexo de forças - pode e deve ser transformado.

No entanto, tal ruptura requer o desenvolvimento de uma análise crítica que torne possível fazer a correlação necessária entre eventos históricos e condições sociais, a fim de se compreender a realidade em sua totalidade e globalidade. Consequentemente, a análise da história mundial a partir da perspectiva dos oprimidos nos permite compreender mais facilmente que os oprimidos, em geral, foram e continuam a ser vítimas da história dos colonizadores brancos ocidentais - uma história que sumariamente nega a milhões de pessoas e comunidades o direito de serem agentes de sua própria história. Essa negação tornou quase impossível para os oprimidos manterem e desenvolverem suas línguas, tradições e culturas. Tomando como exemplo os povos indígenas, a negação do direito à vida está associada ao apagamento da sua história, o que pode ser entendido também como um atentado à biodiversidade, uma vez que o seu modo de vida tem como princípio a preservação das espécies e ecossistemas. Portanto, as lutas indígenas por terra e território - que vão contra os interesses do agronegócio e da mineração - têm a importância de demonstrar o potencial 
Ensino, Saúde e Ambiente - v. 14 n. esp. (2021): Dossiê Paulo Freire para além dos 100 anos: construir utopias, transformar a realidade, p. 189-200.

\section{Lutas Sociais e Educação Popular}

destrutivo do capitalismo, que inexoravelmente conduz a humanidade ao colapso social, ambiental e climático.

Neste texto, buscamos trazer elementos que auxiliem na compreensão da arquitetura global da atual pandemia, intentando ir além da amnésia histórica que fornece visões seletivas da realidade, que são interpretadas quase sempre a partir da perspectiva das nações dominantes e impostas por meio de rígido controle dos modelos educacionais e da mídia.

Com efeito, a pandemia da COVID-19 exige uma resposta crítica que se recuse a cair na tentação de voltar ao "normal" ou adotar postura de aceitação resignada das vidas perdidas em decorrência não apenas do vírus, mas principalmente do desprezo dos dominantes pela vida humana.

Desta forma, buscamos ir além da denúncia da "normalidade" neoliberal e seus efeitos na educação, no meio ambiente, na vida das populações e na arquitetada "crise dos refugiados", para defender uma educação crítica, centrada na igualdade e na defesa da vida.

\section{A ARQUITETURA DA NORMALIDADE CAPITALISTA}

A intensificação dos níveis de extrema pobreza e miséria em nível global foi desencadeada não pela emergência da pandemia da COVID-19, mas principalmente por governantes que desde a década de 1970 abraçaram o édito neoliberal de Milton Friedman que afirma que "a responsabilidade social dos negócios é aumentar seus lucros" (FRIEDMAN, 1970).

Como isso sugere, a principal preocupação da empresa capitalista não é apenas aumentar os lucros dos acionistas, mas também sequestrar o Estado - e, ao fazê-lo, consagrar um tipo de liderança política que abdica de qualquer responsabilidade ética e moral com o bem público. Consequentemente, o neoliberalismo abraçado por Margaret Thatcher (no Reino Unido) e Ronald Reagan (nos Estados Unidos) foi imposto aos cidadãos de seus respectivos países e às economias dependentes sob a rubrica do "livre comércio", que "habilmente esconde, ou busca obscurecer, uma nova edição intensificada desse terrível mal que é o capitalismo histórico, mesmo que a nova edição seja um tanto modificada em relação às versões anteriores" (FREIRE, 1998, p. 114).

Portanto, precisamos situar a análise da atual pandemia em uma visão mais abrangente dos fatores de intersecção que deram origem à pandemia da COVID-19, em primeiro lugar, e também como esses fatores interagiram para produzir o contexto político 
Ensino, Saúde e Ambiente - v. 14 n. esp. (2021): Dossiê Paulo Freire para além dos 100 anos: construir utopias, transformar a realidade, p. 189-200.

\section{Lutas Sociais e Educação Popular}

que impulsionou o crescimento mundial da direita ultraconservadora e seu racismo letal (no Brasil, nos Estados Unidos, no Reino Unido, entre outros países).

$\mathrm{Na}$ maioria das nações desenvolvidas e países em desenvolvimento, como o Brasil, cortes draconianos nas políticas de educação e saúde e desinvestimentos em habitação popular levaram a uma turbulência sem precedentes, especialmente quando medidas de austeridade ditadas pela oligarquia mundial foram implementadas. Conforme Amy Goodman e Noam Chomsky (2021) apontam, é preciso compreender as interconexões entre a pandemia, a desregulamentação das políticas ambientais, as políticas externas e o imperativo capitalista da maximização dos lucros.

Neste sentido, as políticas de saúde não podem ser compreendidas em isolamento, pois estão entrelaçadas, por exemplo, com a política externa adotada por cada governo - fator que incidiu na dinâmica de produção e distribuição das vacinas contra a COVID-19. A análise de Chomsky aponta que a pandemia da COVID-19 está longe de ser o maior fator de ameaça ao futuro da humanidade. Por exemplo, um "estudo de 2015 realizado por Karesh descobriu que as mudanças no uso da terra, como o desmatamento, a expansão urbana e a construção de estradas são os principais impulsionadores do transbordamento de patógenos da vida selvagem para os humanos"

A COVID-19 não é a primeira pandemia experimentada no século XXI - pense em Ebola, Zika, febre amarela, entre outros - e nem será a última, a menos que os governantes mudem imediatamente o paradigma e assumam o objetivo político de reverter as atrocidades das medidas neoliberais de austeridade e de transferência da riqueza da população para as oligarquias financeiras - como Trump fez quando esteve na presidência dos Estados Unidos.

Ao invés de se ocuparem buscando soluções capazes de reverter este trágico cenário, os apologistas do mercado vão a extremos delirantes para fazer a irrealidade parecer normal. Como exemplo, em março de 2020, - quando a pandemia da COVID-19 já havia feito centenas de vítimas no Brasil - o presidente brasileiro, Jair Bolsonaro, defendeu que a falta de acesso a sistemas de saneamento básico para milhões de brasileiros deveria ser vista com bons olhos, pois fortaleceria sua imunidade. Conforme afirmou, "eles nunca pegam nada. Você vê um cara pulando no esgoto, sai, dá um mergulho né? E nada acontece com ele."²

\footnotetext{
1 The Nation, 14 de dezembro de 2020. Disponível em: https://www.thenation.com/article/world/one-healthpandemic/

2 "Jair Bolsonaro claims Brazilians 'never catch anything' as Covid-19 cases rise," The Guardian, 27 de março de 2020. Disponível em: https://www.theguardian.com/global-development/2020/mar/27/jair-bolsonaro-claimsbrazilians-never-catch-anything-as-covid-19-cases-rise
} 
Ensino, Saúde e Ambiente - v. 14 n. esp. (2021): Dossiê Paulo Freire para além dos 100 anos: construir utopias, transformar a realidade, p. 189-200.

\section{Lutas Sociais e Educação Popular}

A crescente consciência acerca do fato de que dois bilhões de pessoas atualmente vivem em nações atormentadas por problemas de escassez de água e de que a previsão é que cerca de dois terços do mundo poderão enfrentar este problema dentro de quatro anos não impediu que, em dezembro de 2020, a água fosse introduzida como uma commodity a ser comercializada no mercado financeiro de Wall Street. ${ }^{3}$

Diante da pandemia da COVID-19, uma das premissas neoliberais que orientam o cenário político global - a premissa declarada pelo presidente Ronald Reagan em seu discurso inaugural, em 1981, de que "o Estado não é a solução para o nosso problema, o Estado é o problema" - foi colocada em xeque até mesmo por instituições-chave do neoliberalismo, como o Fundo Monetário Internacional (FMI). No final de 2020, o FMI passou a recomendar que os governos resistissem "ao endurecimento da política fiscal e, em vez disso, garantissem apoio contínuo ao setor da saúde, aos indivíduos e às empresas. Em economias limitadas em sua capacidade, uma reorientação de priorização dos gastos pode ser tomada para proteger os mais vulneráveis." 4 Contudo, não é possível afirmar que estamos prevendo o fim do neoliberalismo. O que podemos documentar é que a pandemia revelou o fracasso total do neoliberalismo em sustentar a vida neste planeta.

Ademais, a extrema direita alçada ao governo em diversos países intentou encobrir o total fracasso em estancar a pandemia usando uma linguagem de guerra - que é ecoada tanto nos mais altos círculos de poder quanto nos aparatos culturais da direita - para transformar o trauma, a exaustão e o luto em uma névoa de teorias da conspiração, repressão estatal e um profundo sentimento de insegurança que serve principalmente aos interesses dos que estão no poder (GIROUX; FILIPPAKOU, 2021). Como exemplo, em 2020, sob o pretexto de conter a pandemia, o governo Trump seguiu sua agenda racista endurecendo a repressão na fronteira do México com os Estados Unidos e prendendo pessoas em acampamentos improvisados de arame farpado (MACRINE, 2021).

A sistemática violação de direitos humanos nas fronteiras é justificada sob o discurso da segurança - discurso que historicamente faz com que o governo dos Estados Unidos obtenha apoio para fomentar guerras ao redor do mundo. É preciso ressaltar que as mesmas guerras desalojam e deslocam milhares de pessoas que não têm outra opção a não ser buscar

\footnotetext{
${ }^{3}$ Kim Chipman, "Water joins gold and oil for first time as traded commodity on Wall Street amid fears of scarcity,” Financial Post, 8 de dezembro de 2020. Disponível em: https://financialpost.com/investing/waterjoins-gold-and-oil-for-first-time-as-traded-commodity-on-wall-street-amid-fears-of-scarcity

${ }^{4}$ Blog do FMI, 2 de novembro de 2020. Disponível em https://blogs.imf.org/2020/11/02/the-crisis-is-not-overkeep-spending-wisely/ 
Ensino, Saúde e Ambiente - v. 14 n. esp. (2021): Dossiê Paulo Freire para além dos 100 anos: construir utopias, transformar a realidade, p. 189-200.

\section{Lutas Sociais e Educação Popular}

refúgio em qualquer lugar e de qualquer maneira. O mesmo ocorre na União Europeia. Conforme apontado por Tsiakalos (TSIAKALOS et al, 2021), a narrativa hegemônica sobre o suposto perigo dos refugiados passou a ser reforçada por um argumento adicional: além de serem perigosos para a segurança nacional e dos cidadãos individualmente, e para a identidade nacional, os refugiados agora seriam perigosos transmissores do vírus.

A narrativa do suposto perigo dos refugiados esconde o propósito de manter uma reserva de força de trabalho extremamente barata disponível para ser explorada em condições muitas vezes degradantes. Um exemplo é apresentado por Vittoria e Muraca (2021), que relatam as intervenções do governo italiano durante a pandemia da COVID-19 para atender aos interesses das indústrias agrícolas: alguns imigrantes que trabalhavam ilegalmente na agricultura tiveram a sua condição temporariamente legalizada, contudo, sob condições muito precárias e sem garantia de quaisquer direitos sociais básicos, como acesso à educação.

Portanto, a pandemia ofereceu aos governos novas oportunidades para privação de direitos, principalmente de estrangeiros que já são comumente considerados suspeitos de serem perigosos. Nestes casos, a violação de direitos é mais facilmente aceita. No entanto, as violações de direitos nos "casos especiais" para proteger de supostos perigos têm se mostrado como sendo apenas o primeiro passo para outras violações e destituições de direitos.

Desta forma, a ideologia neoliberal do "novo normal" - termo comumente usado para descrever nossa coexistência alterada após a pandemia - induz a aceitação de um futuro de medo no qual não há alternativas, o que intencionalmente produz fatalismo, desesperança e resignação. Conforme apontado por Leher (2021), o termo "novo normal" é polissêmico e denota a confluência de muitas perspectivas diferentes para o futuro, todas elas pró-sistêmicas.

No propagado "novo normal", a perspectiva é de intensificação da exploração do trabalho, principalmente por meio de plataformas e aplicativos de prestação de serviços - na chamada gig economy. Estima-se que, em 2020, cerca de 35\% da força de trabalho nos EUA (57 milhões de pessoas) esteve sob esta condição. De acordo com artigo publicado pela revista Forbes, a previsão é de que, até 2023, este tipo de trabalhador "autônomo" representará mais da metade da força de trabalho nos EUA. ${ }^{5}$

O cenário de demissões em massa de professores durante a pandemia também abriu as portas para a gig economy na educação. Conforme é apontado por Leher (2021), antes da pandemia, o fenômeno da demissão em massa já estava atingindo proporções escandalosas

\footnotetext{
${ }^{5}$ Rebecca Henderson, "How COVID-19 Has Transformed The Gig Economy," Forbes, 10 de dezembro de 2020. Disponível em: https://www.forbes.com/sites/rebeccahenderson/2020/12/10/how-covid-19-has-transformed-thegig-economy/?sh=22c4dfef6c 99 
Ensino, Saúde e Ambiente - v. 14 n. esp. (2021): Dossiê Paulo Freire para além dos 100 anos: construir utopias, transformar a realidade, p. 189-200.

\section{Lutas Sociais e Educação Popular}

nas instituições de ensino superior privadas brasileiras devido à expansão do ensino à distância. Em grande parte das universidades nos Estados Unidos, o número de docentes não efetivos supera significativamente o número de docentes efetivos. Os docentes não efetivos (chamados de adjunct), em geral, estão sob condições contratuais que não proporcionam segurança no emprego, recebem menos benefícios, estão sujeitos a maior servidão e, portanto, dispõem de nenhuma liberdade acadêmica.

A partir da irrupção da pandemia da COVID-19, instituições educacionais no mundo todo migraram de aulas presenciais para aprendizagem remota - um termo que abrange tanto a entrega de conteúdo escolar por rádio, televisão e apostilas, quanto por meio de plataformas educacionais online, software e aplicativos. A difusão deste modelo educacional remoto "préembalado" permite grande controle corporativo sobre o ensino e a aprendizagem, o que faz levantar importantes debates sobre "imperialismo cultural" (BORG; MAYO, 2021) e desqualificação dos professores. Além disso, a exacerbação da desigualdade social e, mais precisamente, as dificuldades no acesso à alimentação, habitação, saúde, medidas de alívio financeiro e políticas de acesso à internet, criaram enormes abismos de desigualdade educacional que alcançaram, em todo o mundo, proporções ainda desconhecidas.

Desta forma, a ideologia do "novo normal", difundida sob o lema do "progresso", escancara a completa demolição da propagada "ética universal de defesa dos direitos humanos" e, especialmente, do direito à vida - que, é preciso ressaltar, historicamente é negado a uma grande parte da população mundial, especialmente aos povos indígenas, comunidades negras e mestiças, mulheres e pessoas LGBT.

No entanto, ondas de protestos ao redor do mundo demonstram um crescente nível de conscientização e organização popular. Um pouco antes do surto da COVID-19, a rebelião popular de outubro de 2019 no Chile - quando os manifestantes marcharam contra o sistema que negava direitos de seguridade social, educação, saúde e moradia - conseguiu aprovar a revogação da Constituição promulgada durante a ditadura de Pinochet nos anos 1980 (FERNÁNDEZ et al, 2021).

As manifestações ao redor do mundo em repúdio ao assassinato de George Floyd (um homem negro desarmado) por um policial branco em Minneapolis, EUA, em maio de 2020, demonstram que a lenta asfixia inerente ao sistema capitalista - que "atinge, em sua cruzada globalizante, a máxima eficácia da natureza maligna" (FREIRE, 1998, p. 114) - está sendo desafiada por aqueles que lutam diariamente para poder respirar. Essas revoltas vêm 
Ensino, Saúde e Ambiente - v. 14 n. esp. (2021): Dossiê Paulo Freire para além dos 100 anos: construir utopias, transformar a realidade, p. 189-200.

\section{Lutas Sociais e Educação Popular}

servindo como plataformas para denunciar o racismo, sexismo, classismo, homofobia e demais opressões enraizadas nas formas capitalistas de exploração.

$\mathrm{Na}$ esteira da pandemia da COVID-19, é imprescindível que os educadores recusem tanto o retorno ao antigo "normal", quanto a aceitação de uma "nova normalidade" neoliberal ou ultraneoliberal - como é o caso no Brasil, em que alterações constitucionais recentes reduzem drasticamente os investimentos públicos em políticas sociais.

O conceito de alienação, desenvolvido por Marx no século XIX, mostra-se bastante atual para compreender a arquitetura da "normalidade" capitalista. No capitalismo, os meios de produção (terras, máquinas e, atualmente, tecnologias) estão concentrados no regime de propriedade privada (incluindo a propriedade intelectual e as patentes, o que dificulta o acesso ao conhecimento). Aqueles que não possuem os meios de produção tornam-se dependentes da venda de seu trabalho para garantir seu sustento. Assim, a alienação do trabalho se constitui na separação, desvinculação do trabalhador: 1) do objeto produzido por seu trabalho; 2) do conjunto de conhecimentos que compõe as diferentes etapas do processo de trabalho; 3) da característica fundamental do ser humano que é sua criatividade para transformar a natureza e se transformar nesse processo; 4) dos outros seres humanos e da natureza.

Esse fenômeno observado por Marx alcançou, na segunda década do século 21, níveis altamente destrutivos nos quais a desumanização é tão acentuada que muitas vezes leva os trabalhadores a buscarem ativamente caminhos que os conduzem ao seu próprio aniquilamento. Alguns exemplos são o apoio de trabalhadores a presidentes como Trump, nos Estados Unidos, e Bolsonaro, no Brasil, entre outros políticos de direita ao redor do mundo, que negam a gravidade da COVID-19 e espalham mentiras sobre a sua letalidade ou negam a própria existência da doença, enquanto os dados oficiais informam os altos números de vítimas fatais.

\section{POR UMA EDUCAÇÃO RADICALMENTE CENTRADA NA VIDA}

A partir do exposto, defendemos que a concepção de uma normalidade que seja verdadeiramente nova só é possível se construída coletivamente pelos povos e grupos sociais oprimidos, de forma a desconstruir a adaptabilidade (quase que "natural") a uma ordem na qual os lucros são colocados acima da vida. A pandemia da COVID-19 deixou claro que é preciso desconstruir a lógica neoliberal de que todos os problemas são uma questão de responsabilidade individual - uma lógica profundamente arraigada na sociedade e que 
Ensino, Saúde e Ambiente - v. 14 n. esp. (2021): Dossiê Paulo Freire para além dos 100 anos: construir utopias, transformar a realidade, p. 189-200.

\section{Lutas Sociais e Educação Popular}

desresponsabiliza o Estado do dever de prover políticas sociais, principalmente aos mais desfavorecidos.

Portanto, afirmamos que, para aqueles de nós que ousam imaginar um mundo menos perverso e mais humano, é preciso lutar pela erradicação dos privilégios de classe, raça, gênero e etnia, um vez que qualquer forma de privilégio aponta para desigualdades estruturais ossificadas que sustentam a economia de mercado, que perpetua seu poder por meio de apelos desavergonhados de "adaptabilidade a situações que constituem uma negação da humanização [e que] são aceitáveis apenas como consequência da experiência de ser dominado ou escravizado" (FREIRE, 1998, p. 72).

Deveria ser radicalmente inaceitável falar de democracia, por exemplo, nos Estados Unidos, que é a sociedade mais rica do mundo e um país no qual milhões de desabrigados, incluindo famílias inteiras e cerca de 16 milhões de crianças, passam fome. Deveria ser motivo de repreensão pública o fato de os Estados Unidos - uma nação que se orgulha de sua abundante produção de alimentos - pagar aos fazendeiros para não plantarem, fazendo com que a escassez de alimentos e os altos preços possam sempre garantir lucros obscenos ao agronegócio. Também deveria ser radicalmente inaceitável que em um país como o Brasil onde existe um sistema de saúde público robusto e uma longa tradição de campanhas de vacinação - o governo atue dificultando a execução de programas de vacinação contra a COVID-19 ou que pacientes com COVID-19 e bebês prematuros morram devido à falta de remédios e suprimento de oxigênio, como ocorreu em 2020 no estado do Amazonas.

Uma normalidade genuinamente "nova" também tornaria inaceitável o governo dos Estados Unidos impor sanções a Cuba, Venezuela, Irã ou qualquer outro país que siga seu próprio caminho de desenvolvimento. Uma nova normalidade significaria que os governos dos Estados Unidos, Reino Unido e União Europeia deixariam de desrespeitar a dignidade, a humanidade e os direitos dos povos da África, América Latina e Oriente Médio.

Portanto, é urgente restabelecer a relação direta entre a luta pelo direito à educação e a luta pelo direito à vida digna. Em outras palavras, conforme argumenta Loureiro (2021), é necessário desenvolver processos educativos que visem superar as relações sociais regidas pelo capital que, como afirmam Katu, Sánchez e Camargo (2021), fomentam um genocídio ecológico, genético e étnico.

Necessitamos de processos educativos que fomentem nossa capacidade criativa de transcender a mera adaptação à realidade imediata e visível para vislumbrar um novo futuro, transformando assim o curso da história. Neste aspecto, Freire argumenta que, enquanto os 
Ensino, Saúde e Ambiente - v. 14 n. esp. (2021): Dossiê Paulo Freire para além dos 100 anos: construir utopias, transformar a realidade, p. 189-200.

\section{Lutas Sociais e Educação Popular}

animais se adaptam ao seu meio, os humanos são capazes de transformar seu meio como agentes históricos - agentes que podem, simultaneamente, refletir sobre a história que escrevem para depois lerem o que escreveram. Ou seja, os humanos deveriam "alegrar-se em saber disso. . . [somos] seres 'condicionados', mas capazes de ir além de [nosso] próprio condicionamento" (FREIRE, 1998, p. 115-116)

Portanto, é urgente construir uma pedagogia que tenha como finalidade central a construção de uma sociedade em que todos possam ter assegurada uma vida digna e livre de qualquer tipo de opressão. Em outras palavras, uma pedagogia que conduza análises críticas da realidade, encorajando a denúncia da desumanização no capitalismo e nutrindo a capacidade transformadora no sentido da reafirmação do "bem viver" (KATU et al, 2021). Nesse ponto, temos muito a aprender com os povos tradicionais (pescadores artesanais, indígenas, quilombolas, entre outros) cujas atividades produtivas possibilitam práticas de vínculos orgânicos com suas terras e territórios. Conforme pontua Loureiro (2021), para os povos tradicionais, a vida não tem preço e seus territórios não podem ser trocados na forma de mercadorias. O seu caráter tradicional é marcado por uma forma específica de ler o presente considerando o passado, o que permite vislumbrar um futuro sem perdas significativas em termos de costumes, valores, culturas e formas de convivência historicamente viáveis e decisivas para a reprodução da vida (LOUREIRO, 2021).

\section{CONSIDERAÇÕES FINAIS}

Conforme exposto ao longo do texto, os multimilionários e governos apologistas do neoliberalismo usaram a pandemia da COVID-19 como oportunidade para garantir lucros extraordinários, derrubar direitos sociais e toda e qualquer barreira para os negócios, revelando, portanto, o alto grau de desprezo que nutrem pela dignidade e pela vida das pessoas.

A pandemia revelou um grau obsceno de desigualdade, intolerância, racismo e, ainda, consolidou uma "nova normalidade" baseada em níveis extremos de exploração dos trabalhadores.

Construir um "novo normal" que rompa de fato o continuum da história - uma história que produziu e reproduz genocídios de forma permanente - é um desafio que deve ser enfrentado com urgência pelos educadores e por todas as forças progressistas. A defesa das instituições públicas como escolas e universidades públicas, saúde pública e gratuita, seguridade social, moradia e alimentação para todos, e o reconhecimento do direito à terra, território e identidade cultural, fazem parte de uma grande luta em defesa de todas as formas de vida. 
Ensino, Saúde e Ambiente - v. 14 n. esp. (2021): Dossiê Paulo Freire para além dos 100 anos: construir utopias, transformar a realidade, p. 189-200.

\section{Lutas Sociais e Educação Popular}

A afirmação de uma vida com dignidade - independentemente de classe, gênero, raça, orientação sexual ou etnia - precisa ser a base da educação, indo em sentido contrário a uma falsa utopia projetada por e a serviço da classe dominante. Freire se refere a essa utopia como "a utopia de uma minoria" que visa "criar uma sociedade robotizada por máquinas altamente inteligentes que podem substituir homens e mulheres em toda uma gama de atividades" (FREIRE, 1998, p.117).

Desta forma, é necessário que a educação produza e difunda aos trabalhadores, ao redor do mundo, ferramentas que lhes permitam ir além dos chavões oferecidos pela concepção de liberdade dos dominantes, que reduz os cidadãos trabalhadores a meros consumidores de mercadorias produzidas às custas da miséria da sua classe. Em outras palavras, é urgente construir uma educação que faça ruir a arquitetura da normalidade capitalista.

\section{REFERÊNCIAS}

ACCIOLY, I; MACEDO, D. Moving beyond the slow death of neoliberalism to a lifecentered education: An Introduction. In: Education, Equality and Justice in the New Normal: Global Responses to the Pandemic. London: Bloomsbury, 2021.

BORG, C.; MAYO, P. The Lost Generation? Educational Contingency in Viral Times: Malta and Beyond. In: Education, Equality and Justice in the New Normal: Global Responses to the Pandemic. London: Bloomsbury, 2021.

FERNÁNDEZ, M. B.; BARRIOS, I. S.; LIRA, A. Lessons from teacher organizing: Disputing the meaning of teaching and teachers' work during the Coronavirus pandemic in Chile. Em: Education, Equality and Justice in the New Normal: Global Responses to the Pandemic. London: Bloomsbury, 2021.

FREIRE, P. Pedagogy of freedom: ethics, democracy, and civic courage. Lanham: Rowman \& Littlefield Publishers, 1998.

FRIEDMAN, M. The Social Responsibility of Business is to Increase its Profits. The New York Times Magazine, 13 September, 1970.

GIROUX, H. A.; FILIPPAKOU, O. Militarization in a Time of Pandemic Crisis. In: Education, Equality and Justice in the New Normal: Global Responses to the Pandemic. London: Bloomsbury, 2021.

GOODMAN, A.; CHOMSKY, N. Chomsky on Trump's Disastrous Coronavirus Response, Bernie Sanders \& What Gives Him Hope. In: Education, Equality and Justice in the New Normal: Global Responses to the Pandemic. London: Bloomsbury, 2021. 
Ensino, Saúde e Ambiente - v. 14 n. esp. (2021): Dossiê Paulo Freire para além dos 100 anos: construir utopias, transformar a realidade, p. 189-200.

\section{Lutas Sociais e Educação Popular}

KATU, L., SÁNCHEZ, C.; CAMARGO, D.R. Resisting and re-existing on Earth: Politics for hope and 'buen vivir'. In: Education, Equality and Justice in the New Normal: Global Responses to the Pandemic. London: Bloomsbury, 2021

LEHER, R. The "new normal' in education is ultra-neoliberal: In defense of the strategy that breaks with the time continuum. In: Education, Equality and Justice in the New Normal: Global Responses to the Pandemic. London: Bloomsbury, 2021.

LOUREIRO, C. F. B. Environmental education: For a critical renovation alongside the traditional peoples. In: Education, Equality, and Justice in the New Normal: Global Responses to the Pandemic. London: Bloomsbury, 2021.

MACRINE, S. L. Coronavirus Pandemic and the 'Refoulment' of Refugee/Asylum Seekers. In: Education, Equality, and Justice in the New Normal: Global Responses to the Pandemic. London: Bloomsbury, 2021.

TSIAKALOS, G.; MALICHUDIS, S.; PAPANGELI, I. Xenophobic Europe: Racist Policy Towards Refugees. In: Education, Equality, and Justice in the New Normal: Global Responses to the Pandemic. London: Bloomsbury, 2021.

VITTORIA, P.; MURACA, M. Neoliberal recrudescence versus radical transformation of the reality in Italy: What and why must we learn from the coronavirus pandemic?. In: Education, Equality and Justice in the New Normal: Global Responses to the Pandemic. London: Bloomsbury, 2021.

\section{SOBRE A AUTORA E O AUTOR}

\section{INNY ACCIOLY}

É Doutora em Educação, professora da Universidade Federal Fluminense (UFF), pesquisadora do Coletivo de Estudos Marxismo e Educação (COLEMARX/UFRJ), do Laboratório de Investigações em Estado, Poder e Educação (LIEPE/UFRRJ) e do Grupo de Estudos em Educação Ambiental Desde el Sur (GEASur/ UNIRIO). Em 2019, foi eleita para a diretoria do Grupo de Trabalho Paulo Freire, da American Educational Research Association (AERA).

\section{DONALDO MACEDO}

É Professor Emérito de Artes Liberais e Educação na University of Massachusetts, Boston, EUA. É coautor com Paulo Freire do livro Alfabetização: Leitura do Mundo, Leitura da Palavra (1987). Suas publicações incluem os livros Imposed Democracy: Dialogues with Noam Chomsky e Paulo Freire (2012) e Literacies of Power: What Americans Are Not Allowed to Know (2006). 